Nataliya Samoylenko

Sevastopol University for Humanities, Sevastopol, Ukraine

\title{
Internet collaborative projects as an effective educational method in teaching writing
}

Brinton, Snow, and Wesche (1989c: 2) state that in a content-based approach, the activities of the language class are specific to the subject matter being taught, and are geared to stimulate students to think and learn through the use of the target language.

Since the 1980s, interest in project-based learning and its integration into second and foreign language instruction has been growing around the world (Alan \& Stroller 2005, Fried-Booth 1982, 1986, Haines 1989, Legutke 1984, 1985, Papandreou 1994, Sheppard \& Stoller 1995, Stoller 1997, Tessema 2005, Tomei at al. 1999). The term "project" used in EFL context was first proposed by Fried-Booth (1986c: 8). He indicated that language tasks arise naturally from the project itself, "developing cumulatively in response to a basic objective, namely, the project". Haines (1989) defined project work as involving multiskill activities which focus on a theme of interest rather than specific language tasks.

Social demand, insufficient theoretical readiness and, undoubtedly, practical importance of Project Work (PW) in teaching foreign languages actualize a search for new pedagogical conditions which enable training of a future foreign language teacher to use PW in higher school. PW is the most progressive and perspective method of training. PW allows achieving any curriculum goals in real-life teaching and educational process.

Project work is viewed by most of its advocates "not as a replacement for other teaching methods" but rather as "an approach to learning which complements mainstream methods and which can be used with almost all levels, ages and abilities of students" (Haines 1989c: 1). 
The primary characteristics of project work summarized by Stroller (1997) are as follows: project work focuses on content learning through language learning; it is student-centered with the teacher playing a role in offering support and guidance throughout the process; it is cooperative rather than competitive; students can work on their own, in small groups, or as a class to complete a project; it leads to the authentic integration of skills and processing of information from varied sources, mirroring real-life tasks; it culminates in an end product that can be shared with others; it is potentially motivating, stimulating, empowering, and challenging; students can build up confidence, self-esteem, and autonomy as well as improve their language skills, content learning, and cognitive abilities.

The main aim of teaching foreign languages is the formation of communicative competence. $\mathrm{PW}$ in foreign language teaching allows the students to use a foreign language as means of learning, the way of expressing their own ideas, perception and comprehension of other peoples' ideas and that is what develops students' intellectual and creative abilities. The basis of PW is the development of cognitive skills of students, their critical and creative thinking, and the ability to build up their knowledge, skills to feel confident in the current volume of information.

The contemporary teacher should focus on new pedagogical technology; remodel educational process and activity according to demands of the times; be able to work with modern information sources and information technologies; know how to include information and communication technologies (ICT) in students' work with the purpose of their learner-centered education.

It is very important to prepare students to compete in today's global economy by developing student competencies in cross-cultural awareness. As the pace of change quickens in today's world, the challenges of emerging technologies and a globally interdependent economy will demand much of students. They will need skills in technology, language and communication. To function effectively, they must understand and respect other cultures, be able to communicate with those who are culturally different, and understand events in other countries.

Due to profound changes in the modern education system, a lot of new techniques have appeared which present an adequate approach to language teaching in modern conditions. Peculiarity of specialized students' studying concerns the real possibility of practical skills application as well as of direct communication with native speakers. Personal-oriented technologies may form the conceptual basis for content determination of teaching strategies and selection of means of foreign language teaching.

Haines S. (1989) states that project work is becoming an increasingly popular feature within the ELT classroom. Common projects are class magazines, group wall displays about students' countries and designs for cities of the future. A project 
involves students in deciding together what they want to do to complete a project whilst the teacher plays a more supporting role.

Some advantages of project work are:

- Increased motivation-learners become personally involved in the project.

- All four skills, reading, writing, listening and speaking, are integrated.

- Autonomous learning is promoted as learners become more responsible for their own learning.

- There are learning outcomes-learners have an end product.

- Authentic tasks and therefore the language input are more authentic.

- Interpersonal relations are developed through working as a group.

- Content and methodology can be decided between the learners and the teacher and within the group themselves so it is more learner centred.

- Learners often get help from parents for project work thus involving the parent more in the child's learning. If the project is also displayed parents can see it at open days or when they pick the child up from the school.

- A break from routine and the chance to do something different.

- A context is established which balances the need for fluency and accuracy.

Further exploration of this aspect may be found in many sources. Project work has been described by a number of language educators, including Carter and Thomas (1986), Ferragatti and Carminati (1984), Fried-Booth $(1982,1986)$, Haines (1989), Legutke (1984, 1985), Legutke and Thiel (1983), Papandreou (1994), Sheppard and Stoller (1995), and Ward (1988).

Project work is potentially motivating, stimulating, empowering, and challenging. It usually results in building student confidence, self-esteem, and autonomy as well as improving students' language skills, content learning, and cognitive abilities.

Project work is work which focuses on completing a task. Project work normally involves a lot of resources-time, people and materials-and learners practice a range of skills and language systems.

Projects allow students to use their imagination and the information they contain does not always have to be factual. The students introduce themselves and their favourite things.

One of the great benefits of project work is its adaptability. You can do projects on almost any topic. They can be factual or fantastic. Projects can, thus, help to develop the full range of the learners' capabilities. Projects are often done in poster format, but students can also use their imagination to experiment with the form.

Project work, whether it is integrated into a content-based thematic unit or introduced as a special sequence of activities in a more traditional classroom, requires multiple stages of development to succeed. Fried- Booth (1986) proposes an easy-to-follow multiple-step process that can guide teachers in developing and sequencing project work for their classrooms. Similarly, Haines (1989) presents 
a straightforward and useful description of project work and the steps needed for successful implementation.

What are the common characteristics of the projects?

- Hard work. Each project is the result of a lot of hard work. The authors of the projects have found information about their topic, collected or drawn pictures, written down their ideas, and then put all the parts together to form a coherent presentation. Project work is not a soft option.

- Creative. The projects are very creative in terms of both content and language. Each project is a unique piece of communication, created by the project writers themselves.

Personal. This element of creativity makes project work a very personal experience. The students are writing about aspects of their own lives, and so they invest a lot of themselves in their project.

- Adaptable. Project work is a highly adaptable methodology. It can be used at every level of teaching.

In our university and Sevastopol schools all students have to write a research work and to participate in the research work conference. When the time came to choose the research work theme, we decided to explore the impact of Internet assisted collaborative projects. The reason was that I had participated in several such projects myself and had got valuable knowledge and useful experience. Besides, we knew that universities and schools in many countries included such projects as the learning circles in their curriculum and it was also obvious for me that their role in the future would considerably increase taking into consideration the processes of globalization and computerization.

That's why we decided to find out more about the value of collaborative Internet assisted projects as an educational method in teaching writing.

The aim of our research work was to find out how Internet collaborative projects affect the study process and what kind of benefits, if any, they give their participants. In my research work we focused on Internet collaborative projects of I*EARN (International Education and Resource Network), particularly on the concept of the Learning Circles and analyzed their role and benefits in education.

IEARN is a non-profit global network that enables young people to use the Internet and other new technologies to engage in collaborative educational projects that both enhance learning and make a difference in the world.

We think the Learning Circle provides a structural approach to promoting cross-classroom collaboration with telecommunications. For teachers, it provides a way to team-teach with many different teachers in a virtual classroom. Developing working relationships with teachers all over the globe enables teachers to develop a very strong sense of the field of teaching. This professional development is more current and dynamic than more traditional avenues of education. For students, working in a collaborative setting with peers around the world gives them wider 
perspectives on issues and a greater understanding of similarities and differences. The work with others can be a powerful mirror that will help them see who they are, where they live, and who they live with in new way. This project will help students to find richness in cultures developed in different areas and aware they are not to be replaced by anything else, to develop their writing and communication skills in English, ICT skills.

The objectives we settled for ourselves are:

1. getting information about different widely used Internet assisted collaborative projects, their history and implementation;

2. describing the projects in which we took part;

3. doing a research in order to compare the learning process and its results in the class that participated in My Hero project and in the class that studied using traditional methods;

4. summarizing students` and teachers` answers to find out their attitude towards collaborative projects, particularly My Hero, and their opinions about its benefits and effectiveness;

5. making a conclusion about the most important benefits of the project and its impact on the study process.

To achieve my aim and objectives, we used the following methods: searching and studying materials about collaborative projects on the Internet, making a questionnaire and conducting a survey, testing students' progress in learning English in the project and control classes using the tests elaborated at different Universities, consultations with the My Hero project (my.hero.com) coordinator and the teachers using the project method in their work.

In the process of my research work we came to the following conclusions:

1. Collaborative Internet assisted projects, My Hero in particular, are a really useful, effective method that can be integrated in the learning process. It brings students and teachers valuable benefits and stimulates students` learning.

2. The most valuable among the benefits are:

a) new knowledge and experience obtained while participating in the learning circles;

b) improved ICT skills and wider knowledge of computers and the Internet;

c) improved general language skills, especially reading and writing, and knowledge of the vocabulary of a specific topic;

d) experience and skills in teamwork;

e) getting acquainted with and learning about other world cultures;

f) contacts around the world.

3. Participating in My Hero and other projects develops young people's personality, widens their outlook and makes the school life more interesting. 


\section{Guidelines for writing project reports}

The aim of the project report is to communicate the results of your project work to an audience. Your audience might already be well informed in the subject. Your trainers will not usually read your report in order to extract knowledge; instead, they will look for evidence that you understand the material and ideas your report presents. Therefore, your document should not only convey information clearly and coherently (such as numbers, facts or other data), but should also, where appropriate, detail the logical processes you relied upon (such as interpretation, analysis, or evaluation).

\section{Typical Components:}

1. Title Page

2. Summary

3. Introduction

4. Background

5. Discussion

6. Conclusion

7. Recommendations

8. Attachments.

\section{Title Page}

The essential information here is your name, the title of the project, and the date. Be aware of any other information your trainer requires. The title of a report can be a statement of the subject. An effective title is informative but reasonably short. Ornamental or misleading titles might annoy readers.

\section{Summary}

This section states the report in miniature. It summarises the whole report in one concise paragraph of about 100-200 words. It might be useful to think in terms of writing one sentence to summarise each of the traditional report divisions: objective, method, discussion and conclusions. Emphasise the objective (which states the problem) and the analysis of the results (including recommendations). Avoid the temptation to copy a whole paragraph from elsewhere in your report and make it do double duty. Since the summary condenses and emphasises the most important elements of the whole report, you cannot write it until after you have completed the report.

\section{Introduction}

The introduction of a project report identifies the subject, the purpose (or objective), and the plan of development of the report. The subject is the 'what', the purpose is the 'why', and the plan is the 'how'. Together these acquaint the reader with the problem you are setting out to solve.

State the subject and purpose as clearly and concisely as possible, usually in one sentence, called the thesis or purpose statement. 
Use the introduction to provide any background information that the reader will need before you can launch into the body of your paper. You may have to define the terms use in stating the subject and provide background such as theory or history of the subject. Avoid the tendency to use the introduction merely to fill space with sweeping statements that are unrelated to the specific purpose of your report.

\section{Background}

If the introduction requires a large amount of supporting information, such as a review of literature or a description of a process, then the background material should form its own section. This section may include a review of previous research, or formulas the reader needs to understand the problem. In an academic project report, it is also the point at which you can show your comprehension of the problem.

\section{Discussion}

This section is the most important part of your report. It takes many forms and may have subheadings of its own. Its basic components are methods, findings (or results), and evaluation (or analysis). The final report should emphasize evaluation.

Before you begin writing, ask the journalist's questions: Who? When? Where? What? Why? How? The last three in particular will help you focus analysis. Beyond asking these simple questions, you also need to make decisions such as: How do you interpret the data? What is the significance of your findings?

\section{Conclusion}

What knowledge comes out of the report? As you draw a conclusion, you need to explain it in terms of the preceding discussion. Some repetition of the most important ideas you presented there is expected, but you should avoid copying.

\section{Recommendations}

What actions does the report call for? The recommendations should be clearly connected to the results of the rest of the report. You may need to make those connections explicit at this point-your reader should not have to guess at what you mean. This section may also include plans for how further research should proceed. In professional writing, this section often comes immediately after the introduction.

\section{Attachments}

- These will include references and may include appendices. Any research that you refer to in the report must also appear in a list of references at the end of the work so that an interested reader can follow up your work.

- That were part of the research, but would be distracting to the report itself. Refer to each appendix at the appropriate point (or points) in your report. 
In the process of our research work we came to the following conclusions:

1. Collaborative Internet assisted projects, My Hero in particular, are a really useful, effective method that can be integrated in the learning process. It brings students and teachers valuable benefits and stimulates students' learning.

2. The most valuable among the benefits are:

a) new knowledge and experience obtained while participating in the learning circles;

b) improved ICT skills and wider knowledge of computers and the Internet;

c) improved general language skills, especially reading and writing, and knowledge of the vocabulary of a specific topic;

d) experience and skills in teamwork;

e) getting acquainted with and learning about other world cultures;

f) contacts around the world.

3. Participating in My Hero and other projects develops young people's personality, widens their outlook and makes the school life more interesting.

These conclusions can be proved by the results of the survey and tests which are reflected in numerous diagrammes we made. Analysing responses to the questionnaire, we found out that teachers' and students' attitude towards the project they implemented was positive. It`s interesting that after its implementation students`evaluation of the project was much higher than before it, when I asked about their expectations. The survey we conducted showed that ICT skills and writing skills are better and progress in English language learning is faster in the class that participated in the project than in the control class. It can be explained by the longer time students spent working on the computers and by the challenging tasks they had to fulfill. As to the English learning, it was stimulated by the necessity to communicate with foreign partners and the intensive reading and writing assignments they had in the course of the project. Having written my research work, we had to present it at different research work conferences and later at the international conference in the USA as the national winner of Teaching Excellence and Achievement (TEA) Program in 2003.

Doing it, we also mentioned some of such projects' problems the teams faced such as technical breakdowns or an irresponsible partner. But still we are strongly convinced that My Hero and other Internet assisted collaborative projects are a valuable and effective educational method which we hope will spread even wider in the nearest future. 


\section{References}

Alexander, P., Kulikowich, J. and Jetton, T. 1994. The role of subject-matter knowledge and interest in the processing of linear and nonlinear texts. Review of Educational Research, 64, 2, pp. 201-252.

Anderson, J.R. 1990. Cognitive psychology and its implications (3rd ed.). New York: W.H. Freeman.

Bereiter, C., Scardamalia, M. 1993. Surpassing ourselves: An inquiry into the nature and implications of expertise. Chicago: Open Court Press.

Brinton, D., Snow, M. and Wesche, M. 1989. Content-based second language instruction. New York: Newbury House.

Carter, G., Thomas, H. 1986. "Dear Brown Eyes": Experiential learning in a project orientated approach. ELT Journal, 40, 3, pp. 196-204.

Ferragatti, M., Carminati, E. 1984. Airport: An Italian version. Modern English Teacher, 2, 4, pp. 15-17.

Fried-Booth, D. 1982. Project work with advanced classes. ELT Journal, 36, 2, pp. 98-103.

Grabe, W., Stoller, F. 1997. Content-based instruction: Research foundations. In M. Snow, D. Brinton (Eds.), The content-based classroom: Perspectives on integrating language and content. White Plains, New York: Addison Wesley Longman.

Haines, S. 1989. Projects for the EFL classroom. Edinburgh: Thomas Nelson and Sons.

Haines, S. 1989. Projects for the EFL classroom: Resource material for teachers. Walton-on-Thames Surrey, UK: Nelson.

Heilman, J., Stout, M. 2005. Putting Projects into Practice. In K. Bradford-Watts, C. Ikeguchi and M. Swanson (Eds.), JALT2004 Conference Proceedings. Tokyo: JALT.

Henry, J. 1994. Teaching through projects. London: Kogan Page Limited.

I*EARN (International Education and Resource Network), http://www.iearn.org/about

Legutke, M., Thomas H. 1991. Process and experience in the language classroom. New York: Longman.

Legutke, M. Thiel, W. 1983. Airport: Ein project fr der Englischunterricht in klasse 6. Hessisches Institut f r Bildungsplanung und Schulentwicklung (HIBS), Abt. IE, Bodenstedstrasse 7, D 6200 Wiesbaden.

Mach, T., Stoller F., and Tardy, C. 1997. A gambit-driven debate. In D. Brinton, P. Master (Eds.), New Ways in Content-based Instruction. pp. 64-68. Alexandria, VA: TESOL.

Papandreou, A. 1994. An application of the projects approach to EFL. English Teaching Forum, 32, 3, pp. 41-42.

Phillips, D., Burwood, S. and Dunford, H. 1999. Project Airport: Part 1. Modern English Teacher, 11, 4, pp. 10-14.

Sheppard, K., Stoller F. 1995. Guidelines for the integration of student projects in ESP classrooms. English Teaching Forum, 33, 2, pp. 10-15.

Singer, M. 1990. Psychology of language: An introduction to sentence and discourse processing. Hillsdale, NJ: L. Erlbaum.

Stoller, F. 2002. Project work: a means to promote language and content. In J.C. Richards, W.A. Renandya (Eds.), Methodology in language teaching: an anthology of current practice pp. 107-119. Cambridge: Cambridge University Press.

Ward, G. 1988. I've got a project on, New South Wales, Australia: Primary English Teaching Association. 